Biggs, R. \& MacFarlane, R. G. (1957). Human Blood Coagulation and its Disorders, and ed. Oxford: Blackwell Scientific Publications.

Biggs, R., Sharp, A. A., Margolis, J., Hardisty, P. M., Stewart, J. \& Davidson, W. M. (1958). Brit. $\mathcal{F}$. Haemat. 4, I77.

Chalmers, 'T. C., Bigelow, F. S. \& Desforges, J. F. (1954). F. Lab. clin. Med. 43, 5 I I.

Denson, K. W. (1958). Brit. F. Haemat. 4, 313.

Dische, F. E. (1958). Brit. F. Haemat. 4, 201.

Findlay, G. M. (1921). F. Path. Bact. 24, 446.

Howard, A. N. (1958). Brit. F. Nutr. 12, 346.

Koller, F. (1955). Rev. Hemat. ro, 362.

Koller, F., Loeliger, A. \& Duckert, F. (1951). Acta haemat. 6, I.

Lee, R. E. \& Lee, N. Z. (1947). Amer. F. Physiol. 149, 465.

Marx, R. \& Bayerle, H. (1943). Biochem. Z. 315, 366.

Quick, A. J. (1939). Proc. Soc. exp. Biol., N.Y., 42, 788.

Reid, M. E. \& Briggs, G. M. (1953). F. Nutr. 51, 34x.

Roos, J. (1957). Thrombosis et Diathesis Haemorrhagica, I, 471.

Rosenthal, R. L., Dreksin, H. \& Rosenthal, N. (1955). Blood, 1o, 120.

Sullivan, W. R., Gangstad, E. O. \& Link, K. P. (r943). F. biol. Chem. r51, 477.

Wolbach, S. B. \& Bessey, O. A. (1942). Physiol. Rev. 22, 233.

Wolbach, S. B. \& Howe, P. R. (1926). Arch. Path. I, 1.

\title{
Studies on the in vitro conversion of $\beta$-carotene into vitamin $A$ in tissues from the rat, guinea-pig and sheep
}

\author{
By N. A. WORKER* \\ Biochemistry Department, Massey Agricultural College \\ (University of New Zealand), Palmerston North, N.Z.
}

(Received 6 February 1959-Revised 30 Fune 1959)

It is now generally accepted that parenterally administered carotene, provided it is presented in a suitable physical state, can be effectively converted into vitamin $A$ in the animal body (Bieri \& Pollard, I954; Bieri, r955; Kon, McGillivray \& Thompson, I955; McGillivray, Thompson \& Worker, 1956). In all the experiments of these workers aqueous dispersions of carotene in water-miscible surface-active agents of the Tween type (the polyoxyethylenesorbitans) were used.

The site of conversion of injected carotene has not as yet been determined. Bieri \& Pollard (1954) were the first to demonstrate that conversion of intravenously administered carotene into vitamin A was unaffected by removal of the small intestine, the normal site of conversion after oral administration. Later the same authors noted that in nephrectomized rats, and in rats from which up to $75 \%$ of the liver tissue had been removed, the amounts of vitamin A formed after injection were similar to the amounts formed in intact control rats. Kon et al. (1955) have also provided evidence, though of a more indirect nature, that in rats and rabbits conversion of injected carotene occurs away from the intestine and is independent of the presence of the liver.

Recently attempts have been made, in our laboratory, to locate more precisely the site at which conversion of injected carotene occurs. It has been clearly demon-

* Present address: Ruakura Animal Research Station, Private Bag, Hamilton, N.Z. 
strated, for example, that the appearance of vitamin $\mathrm{A}$ in the rat after injection of carotene is in no way affected by complete removal of the liver (McGillivray et al. 1956; Worker, 1956a), stomach, small intestine, large intestine, spleen, pancreas, kidneys, adrenals or gonads (Worker, $1956 a$ ), or by complete removal of all lung tissue (Worker, 1957). Further, it has been clearly established that the amount of vitamin A appearing after injection is little affected by activity of the thyroid (McGillivray $e t$ al. 1956; Worker, 1956b).

Though it appeared probable from these results that no one organ or tissue was specifically involved in the conversion of carotene into vitamin A, the whole matter was examined more fully by means of various in vitro techniques. Three different species already investigated are known to be normally capable of converting injected carotene : the rat (Kon et al. 1955; McGillivray et al. 1956), the rabbit (Kon et al. 1955; Worker, $1956 a$ ), and the guinea-pig (Worker, unpublished). In this communication the results are reported of studies on the metabolism of $\beta$-carotene, and of vitamin $A$ alcohol and vitamin $A$ aldehyde, by different tissues from the rat, the guinea-pig and the sheep.

\section{EXPERIMENTAL}

The methods and materials were essentially as described by McGillivray et al. (1956) and Worker $\left(195^{6} a, b\right)$, with some additions and modifications.

\section{Animals}

Rats. Two different types of animal were used. The first was an inbred Wistar animal similar to that used in previous experiments. The second was an inbred strain of hooded Norwegian. All animals when used were partially deficient in vitamin A and were maintained on the basal diet previously described. In every experiment roughly equal numbers of animals of each type were used.

Guinea-pigs. Guinea-pigs were obtained from the small-animal colony of the College Veterinary Department. They were inbred albino animals and had been maintained throughout life on concentrate cubes and fresh grass. Their blood levels and body stores of vitamin A would, therefore, be expected to lie within the normal range.

Sheep. The two sheep used for supplying blood were pure-bred male Romneys from the College flock and at the time of the experiments were pasturing on a typical mixture of rye-grass and white clover on the College farm.

\section{Preparation of $\beta$-carotene and vitamin $A$}

$\beta$-carotene. The carotene used in these experiments was $100 \% \beta$-carotene as supplied by Eastman Kodak Co.

Vitamin A. The vitamin A used was an oil concentrate of vitamin A ester obtained from Glaxo Laboratories (N.Z.) Ltd. Vitamin A alcohol was prepared by its saponification and chromatography on alumina.

Vitamin $A$ aldehyde. It was prepared, purified and identified as described by Ball, Goodwin \& Morton (I948). 
Dispersions. Aqueous dispersions of carotene, vitamin A alcohol and vitamin A aldehyde in Tween 40 (polyoxyethylenesorbitan monopalmitate, Atlas Powder Co., Wilmington, Delaware) were prepared by a method essentially similar to that of Bieri \& Pollard (1954).

Emulsions. Emulsions of carotene and vitamin A were prepared by the method of Shafiroff, Mulholland, Roth \& Baron (1949). Homogenization was carried out at $3500 \mathrm{lb} / \mathrm{in}^{2}$ in a single-stage, piston-type homogenizer giving an emulsion with average particle size of approximately $0.6 \mu$.

Physiological salines. Salines with Krebs-Ringer phosphate or Krebs-Ringer bicarbonate were prepared as described by Umbreit, Burris \& Stauffer (1947). The solutions were made up at approximately weekly intervals and stored at $5^{\circ}$.

\section{Perfusion experiments}

Perfusion of the intact rat. In preliminary experiments with rats attempts were made to follow the build-up of carotene and vitamin $A$ in individual organs after perfusion of the intact animal with carotene and vitamin $\mathrm{A}$ in warm saline well oxygenated with a gas mixture of $95 \% \mathrm{O}_{2}$ and $5 \% \mathrm{CO}_{2}$ in the absence of the blood. It was achieved by opening the chest cavity, rapidly cannulating the aorta and vena cava immediately above the diaphragm with Nylex tubing of I $\mathrm{mm}$ bore, pumping saline through the animal (at the rate of approximately $20 \mathrm{ml} / \mathrm{min}$ in the direction of normal blood flow) until the liquid leaving the vena cava was colourless, and then perfusing continuously at $37^{\circ}$ with $200 \mathrm{ml} \mathrm{Krebs-Ringer} \mathrm{phosphate} \mathrm{or} \mathrm{bicarbonate} \mathrm{containing} \mathrm{carotene} \mathrm{or}$ vitamin $A$ in Tween for varying periods of from $5 \mathrm{~min}$ to $4 \mathrm{~h}$. For this latter purpose a small perfusion apparatus with a variable delivery rate of from 20 to $50 \mathrm{ml} / \mathrm{min}$, similar in principle to that described by Brauer, Pessotti \& Pizzolato (I95 I), was constructed.

Perfusion of isolated rat organs. In other experiments, also with rats, various isolated organs (e.g. kidney, liver and lung) were perfused with carotene and vitamin A preparations in the same apparatus, in an endeavour to determine the manner in which these preparations were metabolized by the different organs.

Perfusion through the lumen of the intestine. In a further series of experiments involving perfusion through the lumen of the intestine of the rat, both in vivo and in vitro, an apparatus similar in principle to that described by Fisher \& Parsons (I949) was constructed. As pointed out by these authors, the use of such an apparatus offered the advantage of allowing perfusion of oxygenated saline through the lumen of the intestine before the blood supply to the organ was severed. This arrangement was thought to be of some importance since, as has been demonstrated by Fisher \& Parsons (1949), even the briefest anoxia may produce important changes in the intestinal mucosa that far outlast the period of anoxia and may possibly limit success.

The rats were lightly anaesthetized with ether and opened by ventral midline incision. The intestines were cannulated with fine glass cannulas of $3 \mathrm{~mm}$ internal diameter, one cannula being inserted in the region of the pyloric sphincter and the other in the region of the ileo-caecal valve. Circulation of $200 \mathrm{ml}$ of warm oxygenated saline through the lumen of the intestine was begun, and the organ was carefully 
removed from the animal and suspended in a flask of oxygenated saline held at $37^{\circ}$. At this point carotene or vitamin A alcohol or aldehyde was introduced into the fluid passing through the lumen of the intestine and the apparatus left to run for $2-4 \mathrm{~h}$. The circulating fluid was then collected and the intestine removed and assayed for carotene and vitamin $\mathrm{A}$.

\section{Incubation experiments}

Preparation of tissues. Tissues were removed as rapidly as possible from animals (rats and guinea-pigs), after they had been killed by a sharp blow on the head, and immediately placed in chilled Krebs-Ringer solution. They were then either sliced free-hand to a thickness of approximately I $\mathrm{mm}$ or homogenized in a food blender for 5-1o sec with a small amount of saline. These preparations were weighed out in $2-5 \mathrm{~g}$ batches and incubated aerobically for $2-4 \mathrm{~h}$ at $37^{\circ}$ with carotene or vitamin A alcohol or aldehyde in saline ( $\mathrm{g}$ tissue to $10 \mathrm{ml}$ saline). Whole intestines, rapidly removed from the animal after both ends had been sutured and carotene or vitamin A administered by hypodermic syringe into the lumen and, finally, chopped intestines, were also incubated for various periods of from 2 to $16 \mathrm{~h}$.

Incubation of blood. Blood from rats and guinea-pigs was taken by cardiac puncture into an heparinized syringe. Blood samples (normally $20-30 \mathrm{ml}$ ) from sheep, however, were taken into an heparinized container by means of a 15 S.w.G. needle inserted into the jugular vein. The blood was incubated immediately after collection with carotene or vitamin $A$ for periods varying from $5 \mathrm{~min}$ to $\mathrm{I} 6 \mathrm{~h}$ in an atmosphere of $95 \% \mathrm{O}_{2}$ and $5 \% \mathrm{CO}_{2}$.

Measurement of carotene and vitamin $A$. All routine estimations were carried out by the method of Thompson, Ganguly \& Kon (1949) with the modifications described by Kon et al. (I955). The vitamin A content of certain samples was also estimated from the ultraviolet absorption curves, after the three-point correction procedure of Cama, Collins \& Morton (I95I) had been applied.

\section{RESULTS}

\section{Perfusion experiments}

Perfusion of the intact rat. In experiments in which the aorta and vena cava were cannulated, the blood was washed out and the body perfused with a Tween solution of carotene in saline (Table I, Expt I), no build-up of vitamin A in the different organs or tissues of the vitamin A-deficient rat or in the circulating fluid could be demonstrated by the end of $4 \mathrm{~h}$, though carotene was taken up in considerable amounts by the kidney and liver. It was of interest to note considerable amounts of oxidation products of carotene in the vitamin A alcohol fraction on extraction of the circulating fluid after perfusion. That the reading obtained with this fraction was not of true vitamin $\mathrm{A}$ was suspected from the atypical, non-fading, blue-grey colour formed on mixing with antimony-trichloride reagent. The suspicion was confirmed from the ultraviolet absorption curve corrected by applying the three-point procedure of Cama et al. (195I) to the vitamin A-alcohol fraction obtained by chromatography. When the animal was perfused with a Tween solution of vitamin A alcohol in saline, vitamin A 


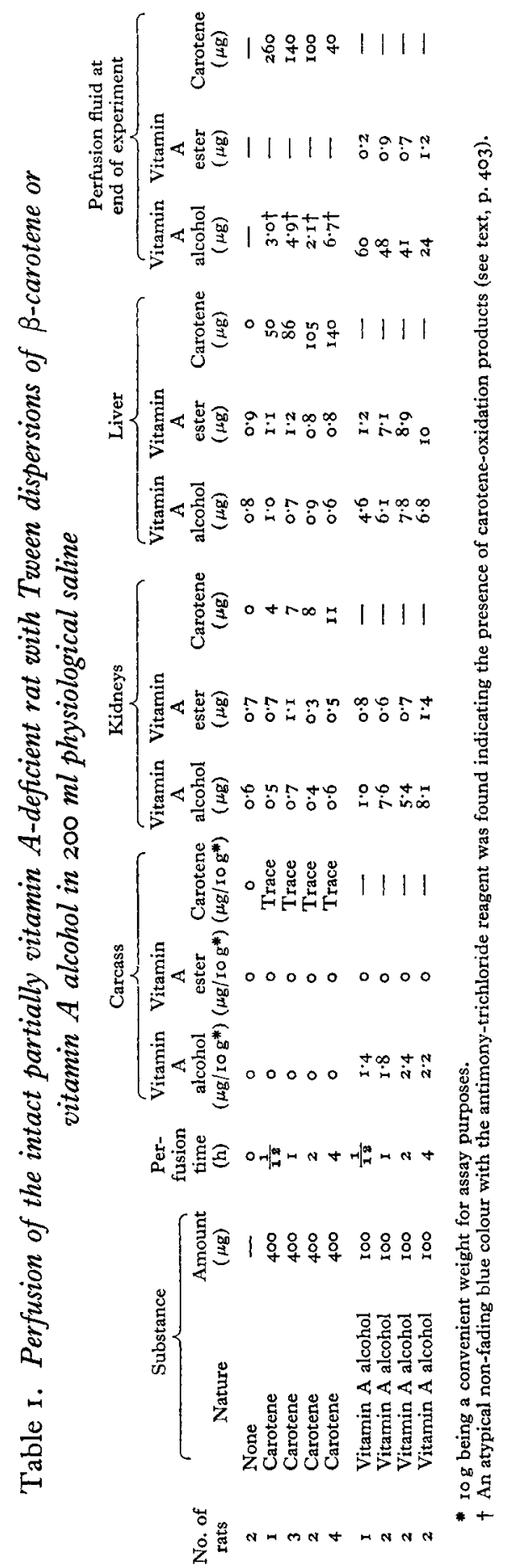

葍宫 
was taken up by the carcass, kidney and liver in various amounts, depending on the perfusion interval (Table I, Expt 2), and it was noteworthy that the vitamin A appearing in the liver after perfusion was mainly in the ester form, whereas that appearing in the kidneys and carcass was still in the form administered.

Perfusion through isolated rat organs. The results of these experiments are presented in Tables 2 and 3. From a consideration of those in Table 2 it will be seen that there was no evidence to indicate formation of vitamin A in the isolated kidney, liver or lung after perfusion with carotene, either as a dispersion in Tween or as an emulsion, although destruction of the circulating carotene was appreciable. In the perfused lung there was a relatively larger breakdown of carotene in Tween (as judged by total recovery) than in the liver or kidney, although storage of carotene in these two organs greatly exceeded that in the lung. The greater breakdown of carotene in the lung was also accompanied by comparatively higher blue readings with the antimony-trichloride reagent. These, however, were non-fading atypical blues; moreover, when the threepoint correction procedure was applied to the ultraviolet spectra of the original solutions, there was no evidence that vitamin $A$ was present. From a comparison of the results obtained after perfusion with carotene as a dispersion in Tween or as an emulsion, it is apparent that the latter is much more readily destroyed than the former, but whether owing to a difference in particle size or to a difference between their relative stabilities in saline is not known.

When vitamin A alcohol, as a Tween dispersion or as an emulsion, was perfused through the individual organs (Table 3 ), a build-up of vitamin A was noted similar to that occurring on perfusion of the intact animal. Further, as in the earlier experiment, the vitamin was observed to be present in the liver mainly as the ester and in the kidney mainly as the alcohol.

Perfusion through the lumen of the intestine. With the technique of Fisher \& Parsons (1949) no vitamin A could be demonstrated in either the intestinal wall or the perfusion fluid after a Tween solution or an emulsion of carotene had been circulated through the isolated intestine for periods of from 2 to $4 \mathrm{~h}$ (Table 4 , Expts I and 2). On the other hand, perfusion of the intact intestine with carotene for 2-4 $\mathrm{h}$ resulted in accumulation in the wall of measurable quantities of vitamin A, in both the alcohol and ester forms. In the latter experiments animals were kept under diethyl-ether anaesthesia throughout the experimental period and, apart from insertion of the cannulas into the intestine and circulation of the perfusion fluid, were not interfered with in any other way. Perfusion of $100 \mu \mathrm{g}$ vitamin A alcohol either as a Tween dispersion or as an emulsion through the isolated intestine by the Fisher \& Parsons (1949) technique resulted in a fairly large build-up of vitamin A (mainly as the ester) in the intestine at 2 and 4 h (Table 4, Expts 3 and 4). Further, the level of blood vitamin A ester (the normal form for transport from the intestine) and the levels of alcohol and ester in the liver were all significantly raised in the intact group after perfusion (not shown in the table). In a single experiment in which $100 \mu \mathrm{g}$ vitamin A aldehyde in Tween were circulated through an isolated surviving intestine, the amount and the form of the vitamin present after perfusion for 2 and $4 \mathrm{~h}$ were similar to those after perfusion with an equivalent amount of vitamin $\mathrm{A}$ alcohol for the same time (Table 4, Expt 5). This 

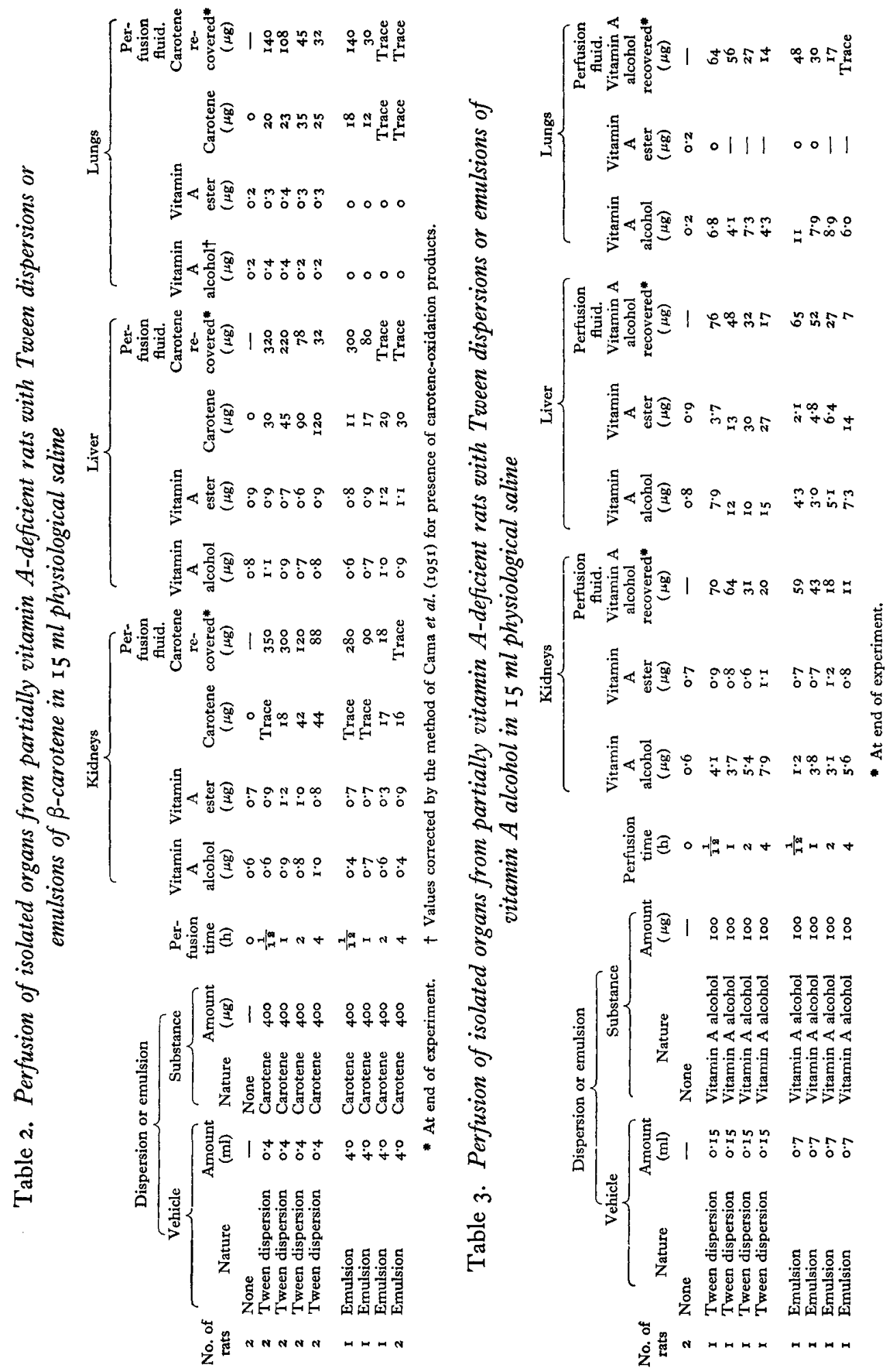
Vol. 13

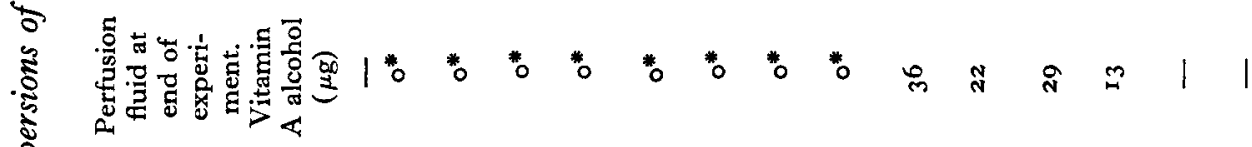

-

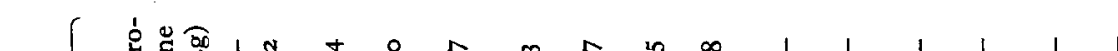

ปั

B.

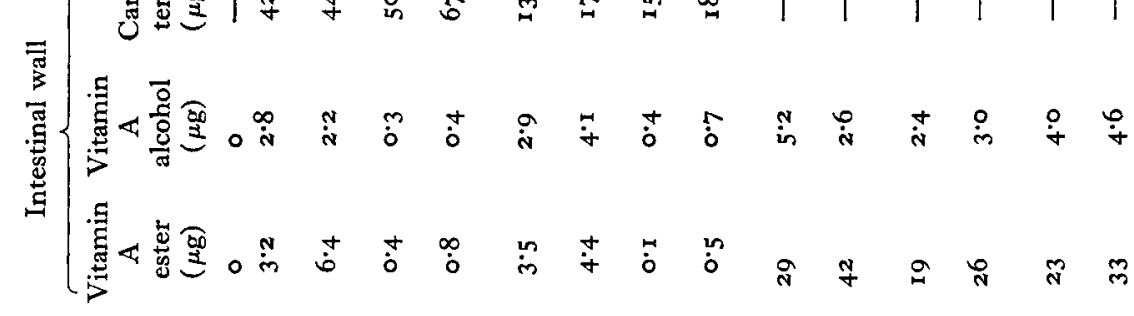

$\therefore$.

t. $\cdot \frac{\sqrt{8}}{8}$

.

. है

క

$\approx$ of

芯各

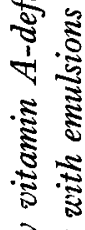

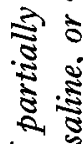

a.

हั้

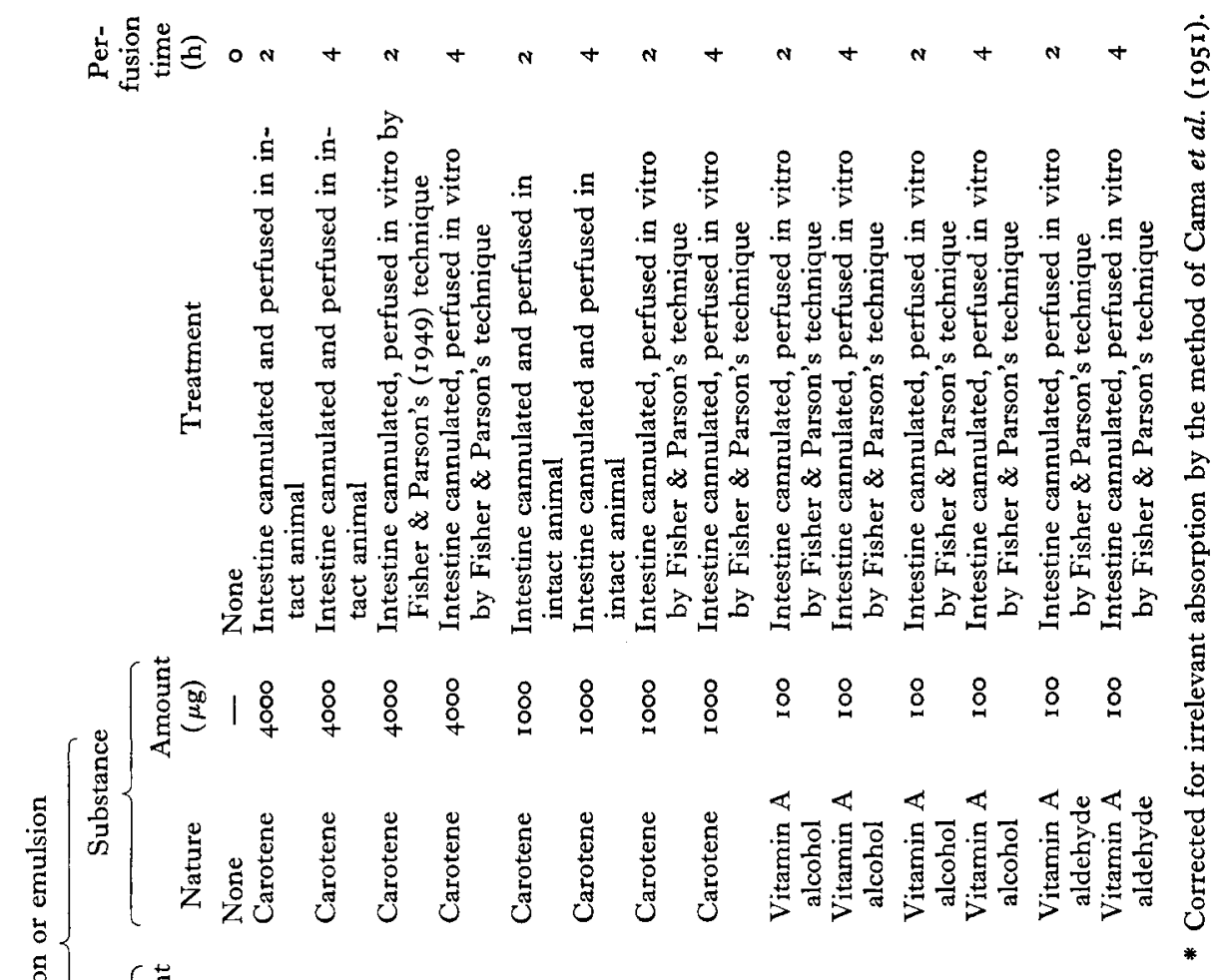

है

๘

s.

논

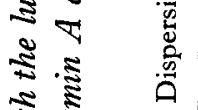

จิ

s

. ำ

ริ

के

$\frac{\dot{+}}{\frac{0}{0}}$

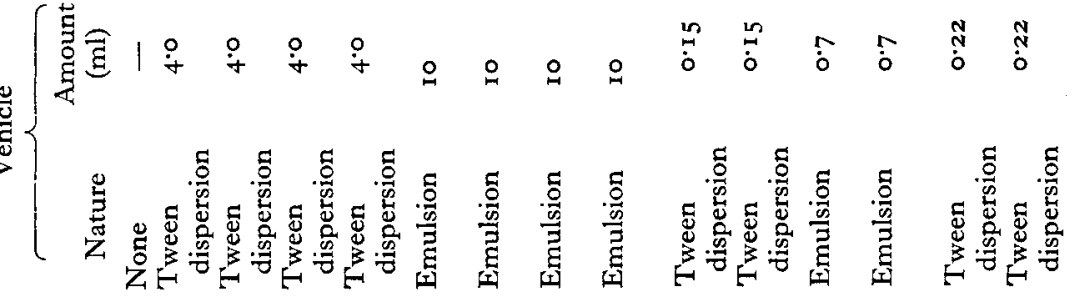
岁驾

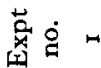


observation was thought to be of considerable significance since it clearly demonstrates that vitamin $\mathrm{A}$ aldehyde, which has been postulated as a possible intermediate product in the conversion of carotene into vitamin A (Glover, Goodwin \& Morton, 1948a), can be absorbed, metabolized to vitamin A alcohol and esterified in the surviving intestine away from the animal body.

\section{Incubation experiments}

Incubation of rat tissues. Table 5 presents the results obtained on incubating tissue slices and tissue homogenates with carotene, vitamin A alcohol or aldehyde in Tween and with carotene and vitamin $\mathrm{A}$ alcohol in emulsified form, for various periods of from 2 to $4 \mathrm{~h}$. From the results of Expt $\mathrm{I}$ it is clear that no vitamin A was formed on incubating carotene, either as an aqueous dispersion or as an emulsion, with tissue slices or homogenates of abdominal wall, intestine, kidney, liver or lung. Allowance had, however, always to be made for the presence of oxidation products of carotene, giving stable but atypical blue colours with the antimony-trichloride reagent, which were found particularly after incubation of carotene as an emulsion, when much of the carotene present was invariably destroyed. Incubation of $80 \mu \mathrm{g}$ vitamin A alcohol in Tween and in emulsified form with tissue homogenates (Expt 2) showed that under the conditions of these experiments the abdominal wall, kidney or lung was unable to esterify the free vitamin either dispersed in Tween or emulsified. Homogenates of intestine or liver tissue, on the other hand, were capable of esterification in vitro, but the reaction with the latter was much slower than with the former. In a further experiment (Expt 3 ) in which roo $\mu \mathrm{g}$ vitamin A aldehyde in Tween were incubated with homogenates of intestine, kidney or liver, about one-third of the dose was recoverable as vitamin $A$ after $2 \mathrm{~h}$ incubation and almost one-quarter after $4 \mathrm{~h}$ incubation. No free vitamin A aldehyde could be identified after incubation, however, which was perhaps to be expected, in view of its somewhat reactive nature.

With whole or chopped intestine (about $\mathrm{I} \mathrm{cm}$ in length), numerous attempts were made to demonstrate the in vitro conversion of carotene into vitamin A. A sample of these results is presented in Table 6 (Expt $\mathrm{r}$ ). Many variations in the incubation interval, in the form and concentration of carotene and in the type of saline, were tried, and several different techniques, as reported by workers who claim to have effected in vitro conversion (e.g. Wiese, Mehl \& Deuel, I947; Rosenberg \& Sobel, I $953 a, b$ ), were exactly repeated but without any apparent success. On the other hand, vitamin A alcohol was rapidly esterified by these preparations (Table 6, Expt 2), the reaction being virtually complete after $3 \mathrm{~h}$. In the light of this result, it should be noted that, if any of the intestinal preparations used had been able to convert carotene into vitamin $\mathrm{A}$ in vitro, the main increase in vitamin $\mathrm{A}$ should have been in the ester form. However, it was certainly not so, the only increase noted being in the vitamin A alcohol fraction; moreover, after correction this increase was shown clearly to be due not to vitamin A but to oxidation products of carotene.

Incubation of guinea-pig tissue. When carotene, either as a dispersion or as an emulsion, was incubated with guinea-pig tissue slices, or homogenates, of abdominal wall, intestine, kidney, liver or lung, there was no evidence to suggest formation of vitamin A 
Vol. 13

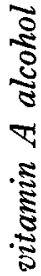

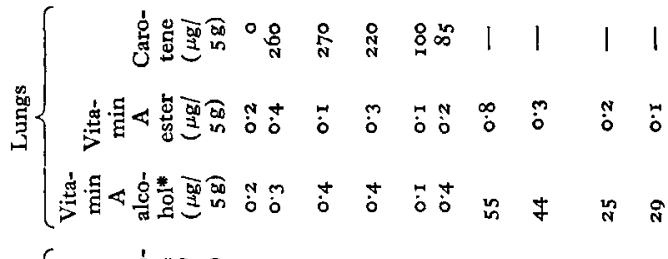

o

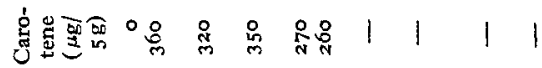

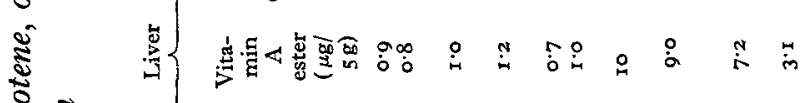

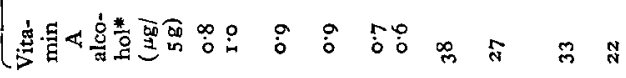

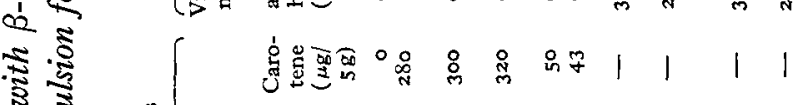

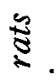

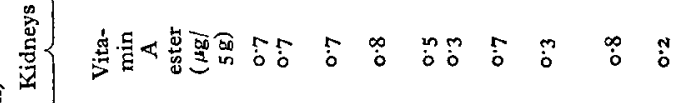

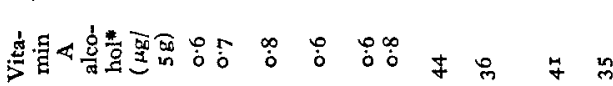

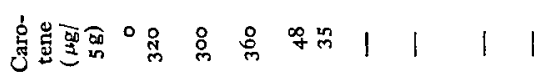

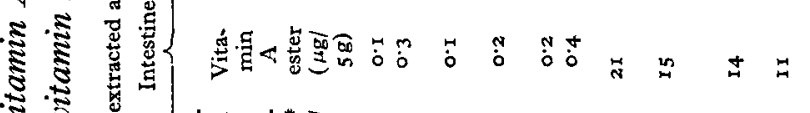

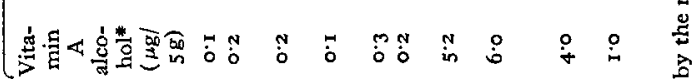

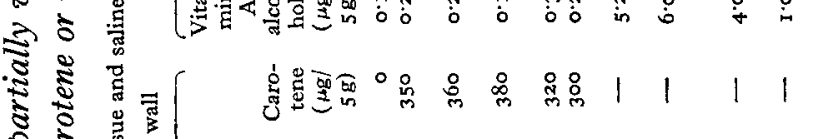
है के

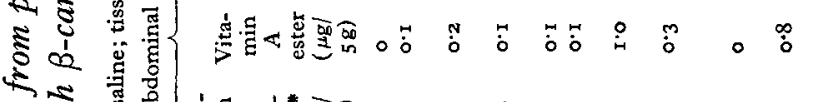

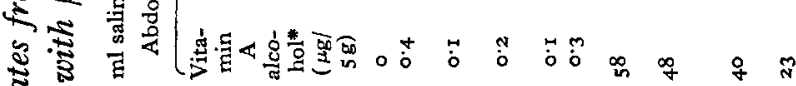

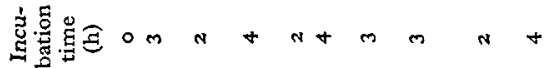

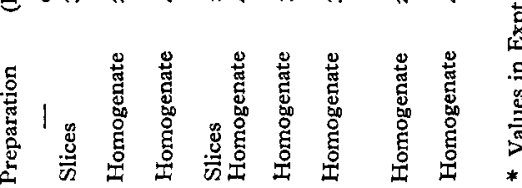

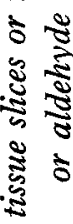

b

胥

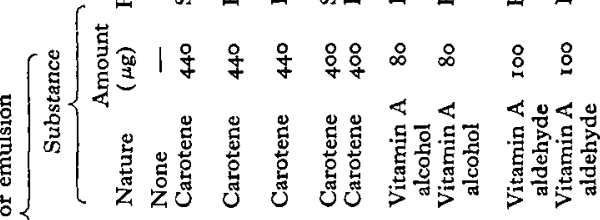

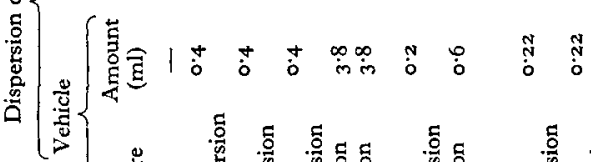

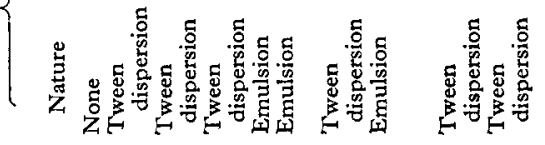

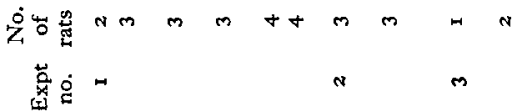

$\stackrel{\frac{0}{2}}{\frac{\pi}{n}}$ 


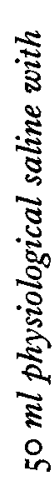

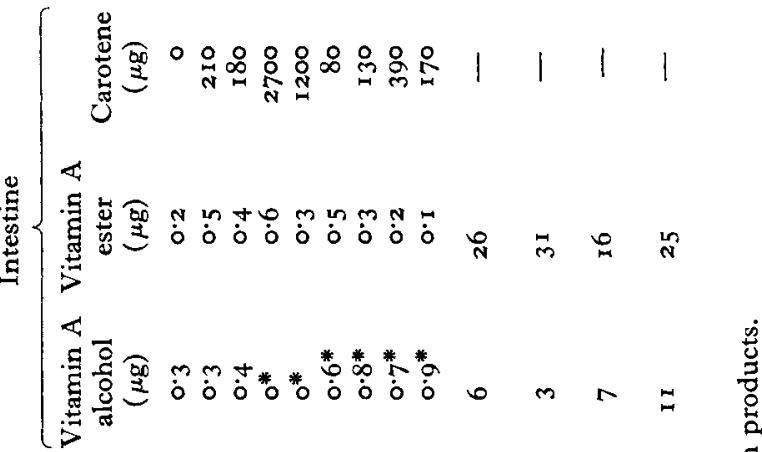

है

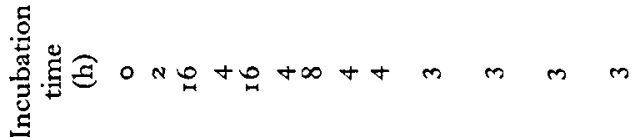

ㄴ.

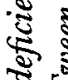

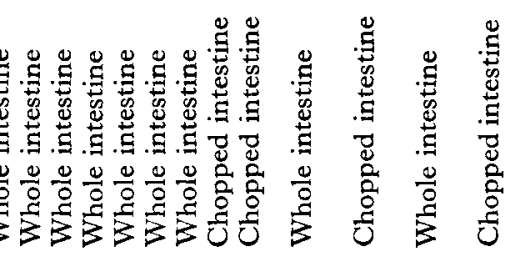

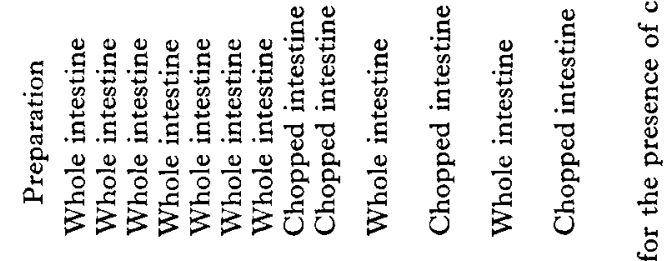

)

है,

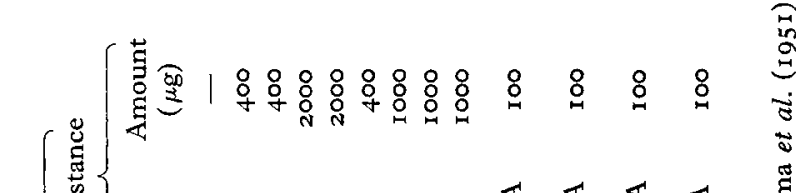

$+\frac{2}{2}$

象

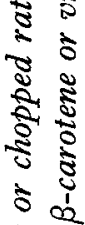

ฐँ

ฐँ

5

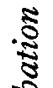

苋

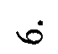

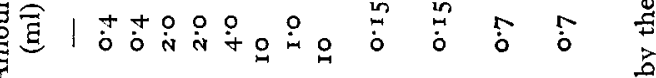

造
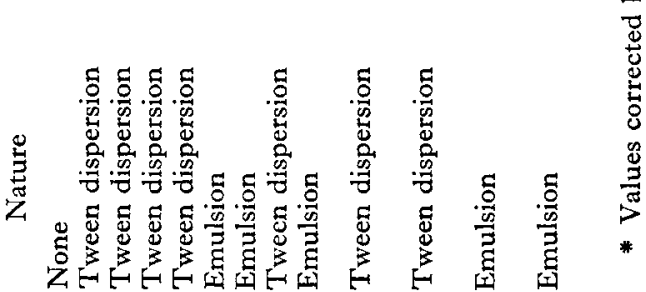

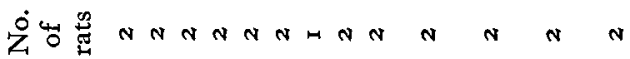

蒙宅- 
by any tissue (Table 7, Expt I). Generally the results obtained and the conclusions drawn were the same as those for the rat and will not be discussed further here.

In contrast, however, the results obtained after incubation of guinea-pig tissue preparations with vitamin A alcohol were markedly different from those with rat tissue (Table 7, Expt 2). Whereas in the rat about half of the vitamin A was recovered after incubation, mainly in the ester form from the intestine or the liver, in the guinea-pig some tissues completely destroyed vitamin A during incubation. After incubation vitamin A was recovered only from the lung preparation (as the alcohol) and from the liver preparation (mainly as the ester). Since the intestinal preparation was so effective in destroying nearly $90 \%$ of the vitamin $\mathrm{A}$ in the dose, one wonders whether in the living animal a similar state of affairs exists and is not the explanation for the extremely poor vitamin A economy of this species.

Incubation of rat, guinea-pig or sheep blood. When blood from rats, guinea-pigs or sheep was incubated for various intervals with a dispersion of carotene in Tween or an emulsion of carotene (Table 8), there was a progressive increase with time in the antimony-trichloride blue colour of the vitamin A-alcohol fraction (but not of the ester fraction) of the plasma. The blue colours obtained were typical and faded normally. When, however, the ultraviolet absorption curves of the original solutions were obtained and a correction was applied by means of the three-point procedure of Cama et al. (195I), no differences could be found between the initial levels of vitamin $A$ in the blood and the levels after incubation with carotene. These observations were thought of significance, since they demonstrate how easy it is to attribute a small increase in blue colour to vitamin A when in fact it may be entirely due to oxidation products of carotene (see also Worker, 1957). This increase is comparatively easy to determine visually when vitamin $A$ is absent from the original preparation, but in the presence of vitamin $A$ the atypical non-fading blue due to oxidation products may be easily masked by the typical fading blue due to vitamin A.

However, in order to check further that the increase in antimony-trichloride blue colour observed on incubation of carotene was in fact due to oxidation products of carotene and not to the presence of true vitamin $A$, an experiment was designed in which a sample of rat blood was distributed over four treatments: (1) blood incubated alone; (2) blood incubated with rat intestinal homogenate; (3) blood incubated with carotene in Tween; (4) blood incubated with carotene in Tween and with rat intestinal homogenate.

The results of this experiment are given in Table 9. From them it can be seen that of the vitamin A alcohol originally present in the control blood (treatment 1 ) all was capable of esterification in the presence of intestinal homogenate and was nearly completely recoverable in the ester fraction after chromatography (treatment 2). Of the apparent vitamin A alcohol present in the blood after incubation with carotene (treatment 3), however, only about one-half (an amount equivalent to that in the control blood) was esterified in the presence of intestinal homogenate and recovered as the ester after chromatography (treatment 4 ). The balance remained still with the alcohol fraction and in the presence of the antimony-trichloride reagent gave a non-fading grey to blue colour, which was quite atypical of true vitamin A but clearly characteristic of the oxidation products of carotene. 


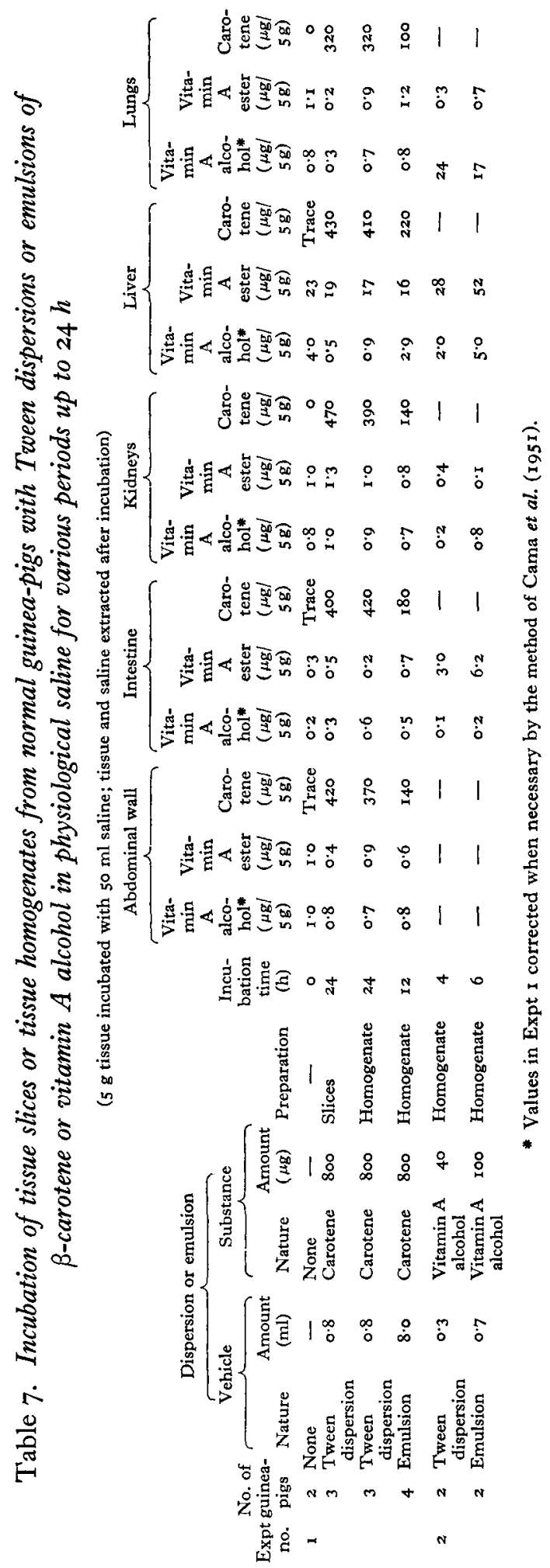




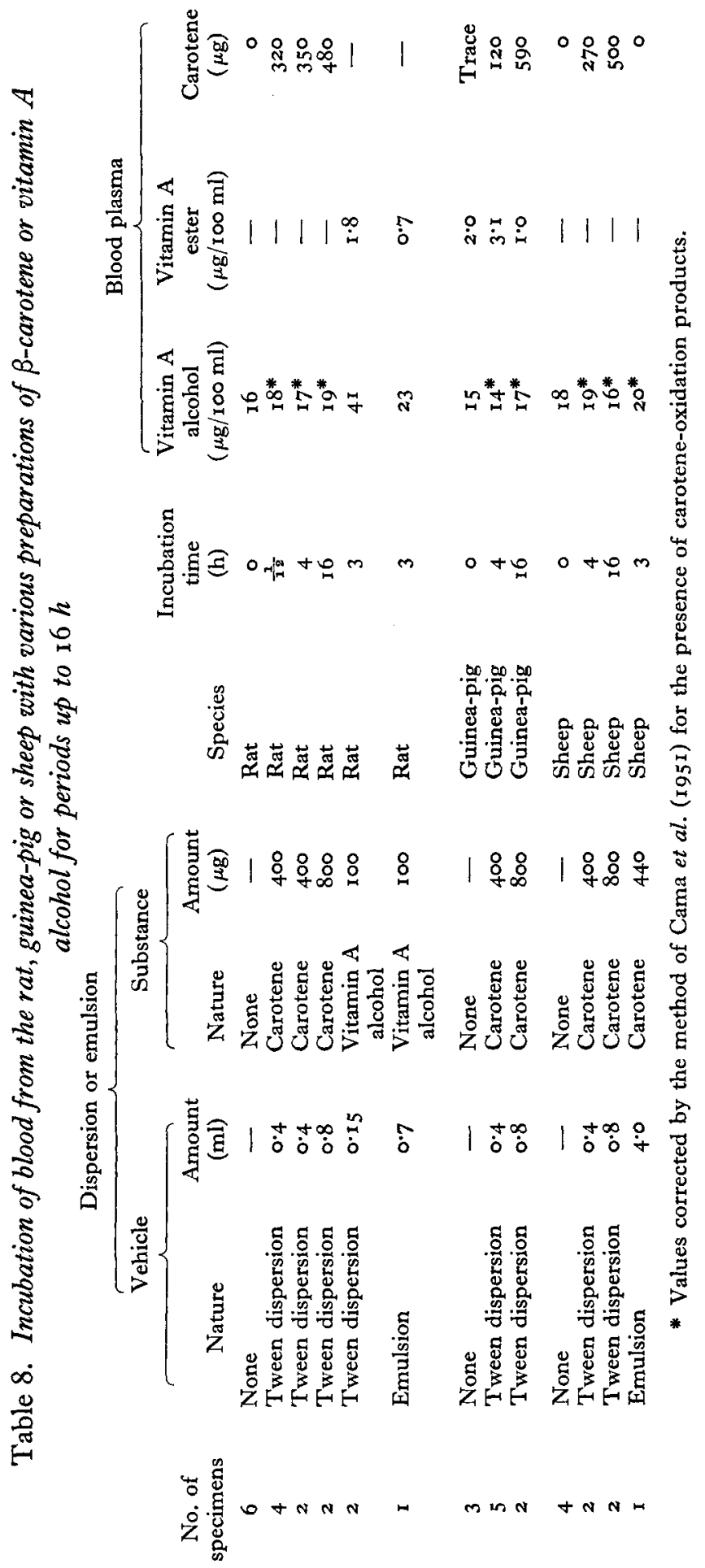


Table 9. Incubation of $10 \mathrm{ml}$ samples of rat's pooled whole blood, separately or in combination, with $\beta$-carotene and with rat intestinal homogenate, to demonstrate esterification of true vitamin $A$ alcohol and its chromatographic separation from oxidation products of carotene interfering with the antimony-trichloride reaction. Incubation time i $h$

\begin{tabular}{|c|c|c|}
\hline & \multicolumn{2}{|c|}{ Blood plasma } \\
\hline reatment & $\begin{array}{c}\text { Vitamin } A \\
\text { alcohol } \\
(\mu \mathrm{g} / 100 \mathrm{ml})\end{array}$ & $\begin{array}{c}\text { Vitamin } A \\
\text { ester } \\
(\mu \mathrm{g} / 100 \mathrm{ml})\end{array}$ \\
\hline l) & $14^{*}$ & $1 \cdot 0$ \\
\hline stinal homogenate & 0 & $10^{*}$ \\
\hline carotene in Tween & $25^{*}$ & $I \cdot 3$ \\
\hline carotene in Tween together with $2 \mathrm{~g}$ & Iot & $12^{*}$ \\
\hline
\end{tabular}

(1) Incubated alone (control)

(2) Incubated with $2 \mathrm{~g}$ intestinal homogenate

(3) Incubated with $400 \mu \mathrm{g}$ carotene in Tween

(4) Incubated with $400 \mu \mathrm{g}$ carotene in Tween together with $2 \mathrm{~g}$ intestinal homogenate

* Normal fading blue with antimony-trichloride reagent.

† Atypical non-fading blue with antimony-trichloride reagent.

\section{DISCUSSION}

Numerous attempts have been made to demonstrate the in vitro conversion of carotene into vitamin $\mathrm{A}$, but the results are for the most part conflicting. Thus, Olcott \& McCann (193 I), Pariente \& Ralli (193 I-2) and von Euler \& Klussmann (1932), in experiments in which minced liver tissue or liver extracts were incubated with colloidal carotene, obtained evidence for the formation of vitamin A by the presence of a typical absorption band at $328 \mathrm{~m} \mu$ or by a positive antimony-trichloride colour reaction. On the other hand, Rea $\&$ Drummond (1932), von Euler (1932) and later Ahmad (1934) were unable to confirm these results, and Drummond \& MacWalter (r 933) could not obtain vitamin A from carotene that had been taken up by the liver cells before mincing and incubation. In critically discussing these findings, Woolf \& Moore (1932) pointed out the difficulties inherent in such studies and the uncertainty of detecting vitamin $\mathrm{A}$ in the small amounts claimed to have been produced; more recently, Glover et al. $(1948 b)$ have noted the difficulty of distinguishing the $335 \mathrm{~m} \mu$ peak of $c i s$-isomers of carotene from that of vitamin A at $325-328 \mathrm{~m} \mu$ when other absorbing substances are present.

More recent studies have likewise produced equivocal results. Thus Wiese et al. (1947) and Rosenberg \& Sobel (1953a,b) observed an increase in vitamin A after incubating the intestines of rats with carotene. A similar result was obtained also by Glover $e$ al. (1948b), but the increase was considered by the authors insufficient for them to assert that in vitro conversion had occurred. In experiments with calf tissues Stallcup \& Herman (1950) demonstrated conversion of colloidal carotene in minced liver preparations and in isolated intestines. Similarly, McGillivray (195 I) obtained evidence of conversion in isolated sections of surviving sheep intestine. In contrast to these findings, however, De \& Sundararajan (I95I) were unable to demonstrate in the rat, and Bieri \& Pollard (1953) in the rat, rabbit or calf, any increase in vitamin A after incubating whole intestine with carotene. Negative results were reported also in the rat by Kon \& Thompson (195I), working in collaboration with R. B. Fisher and D. S. 
Parsons and using the perfusion technique described by the latter (Fisher \& Parsons, 1949).

It is well recognized that a negative result obtained in vitro is a difficult premise from which to argue. For this reason throughout the present work considerable attention was paid to detail and extreme care was taken at all times to ensure that the results obtained were not limited in any way by poor technique. Carotene was prepared in forms known to be effectively utilized in vivo, the incubation and perfusion procedures were standard ones that have been used successfully by numerous other workers studying a variety of different problems, and the extraction, measurement and correction procedures used to estimate vitamin A were ones used routinely in this laboratory and elsewhere with perfectly satisfactory results. Every endeavour was thus made to avoid factors likely to have any possible adverse effect on the outcome of the results. Despite these precautions, however, it was not possible to demonstrate conversion of carotene into vitamin $A$ in vitro, either in the perfused intact animal or in tissue slices or homogenates of body wall, intestine, kidney, liver or lung, or in isolated perfused organs (intestine, kidney, liver or lung) of the rat or guinea-pig. Further it was not possible to demonstrate conversion in the blood of the rat, guinea-pig or sheep.

Though these results clearly confirm those of De \& Sundararajan (I95I), Kon \& Thompson (195I) and Bieri \& Pollard (1953) and contrast with those of Wiese et al. (1947), Rosenberg \& Sobel (1953a,b), Stallcup \& Herman (1950) and McGillivray (195I) and with my own initial observations (Worker, 1957), it is difficult at the present time to offer a completely satisfactory explanation for the conflicting findings. It should be pointed out, however, that in the work of Wiese et al. (1947), Stallcup \& Herman (1950) and Worker (1957), vitamin A was estimated solely by the antimonytrichloride reaction, the validity of which, under such conditions, would appear much open to question (see, for example, p. $4 \mathrm{I}$ I). Further, in the work of Rosenberg \& Sobel $(1953 a, b)$ vitamin A was estimated in intestine by the difference in absorption at $325 \mathrm{~m} \mu$ before and after ultraviolet irradiation, a procedure that, although found reliable for serum by Bessey, Lowry, Brock \& Lopez (1946), has since been shown by Bieri \& Pollard (1953) to be of little use for intestine. For these reasons it is thought that the findings of these workers cannot be accepted as completely demonstrating a significant degree of conversion of carotene into vitamin $A$ in vitro. In a somewhat different category is the work of McGillivray (195 I), in which significant increases in vitamin $\mathrm{A}$, identified both colorimetrically and spectrophotometrically, were found in the isolated intestine of the sheep after incubation with carotene. In the light of the present studies, it is not easy to offer an explanation for this finding unless it is assumed due, at least in some measure, to a species difference in the rate or efficiency of conversion.

The results obtained on perfusing or incubating tissues with vitamin A alcohol or aldehyde support observations made in vivo by other workers. For example, Glover et al. (1948a), have shown that after oral administration vitamin $A$ aldehyde is efficiently converted into vitamin $A$ in the gut wall and after subcutaneous administration in the subcutaneous tissues. In the present experiments vitamin A aldehyde was completely absorbed and efficiently converted into vitamin A (mainly vitamin A 
ester) after perfusion through the isolated surviving intestine for $4 \mathrm{~h}$. Further, after incubation for 2-3 $\mathrm{h}$ with homogenates of abdominal wall, intestine, kidney, liver or lung it was completely metabolized, approximately one-third of the dose being recovered as vitamin A alcohol from abdominal wall, kidney or lung, and as vitamin A ester from liver or intestine. It would appear, therefore, as Glover et al. (I948a) have observed, that the conversion of vitamin A aldehyde into vitamin A alcohol is a simple reduction reaction, the enzymes responsible being widespread throughout the body tissues.

With vitamin A alcohol, esterification in the rat, under the present experimental conditions, was limited to the intestine and liver, and was complete in the former but incomplete in the latter. These observations held good whether the intestine was perfused whole or incubated as slices or as an homogenate, and whether vitamin A was present as a Tween dispersion or as an emulsion. With the guinea-pig, on the other hand, the position was somewhat different. In incubation of vitamin A alcohol in Tween for various periods with homogenates of intestine, kidney, liver or lung, most of it was destroyed by the intestine or kidney. With the lung preparation one-half of the vitamin A originally present was recovered (still as the alcohol), and with the liver preparation somewhat less than one-half of that originally present was recovered as the ester. That the guinea-pig intestine, incubated either whole or as an homogenate, was effective in destroying nearly all the vitamin $\mathrm{A}$ added is, as has been pointed out earlier in this paper, one possible explanation for the poor rate of carotene utilization and the low vitamin A liver reserves in this species (see also Moore \& Sharman, 1951).

The attempts made with various tissue preparations to demonstrate the conversion of carotene into vitamin A in vitro have, unfortunately, not been successful, and for this reason it has not been possible to obtain any further information about which tissues are potentially capable of effecting the conversion of parenterally administered carotene into vitamin $\mathbf{A}$ in the intact animal. From a consideration of the results it would appear that the reaction is an exceedingly difficult one to demonstrate in vitro although the reasons for it are by no means clear. It has been postulated by Glover and his associates (Glover \& Redfearn, 1954; Fazakerley \& Glover, 1957; Fishwick \& Glover, 1957) that the initial reaction in the breakdown of orally administered carotene to vitamin $\mathrm{A}$ involves an oxidative fission of the terminal double bond in the side-chain to form long-chain carotenals, which are then degraded by stepwise oxidation to vitamin $\mathrm{A}$ aldehyde, which is in turn reduced to vitamin $\mathrm{A}$. From the results of the present studies with vitamin $A$ aldehyde and from those obtained in vivo by Glover et al. (1948a), it would appear that the early stages of the reaction (i.e. carotene $\rightarrow$ longchain carotenals $\rightarrow$ vitamin A aldehyde) are those inhibited in vitro. Of the enzyme systems involved in these changes little is known. It would appear, however, on the basis of the results of the experiments reported here that either the enzymes involved must be extremely sensitive to non-physiological conditions or that the necessary co-factors, perhaps supplied from the circulation, are not present in isolated tissues at sufficient concentrations to effect conversion (Bieri \& Pollard, 1953). 
SUMMARY

I. Attempts have been made to demonstrate the in vitro conversion of $\beta$-carotene into vitamin $A$ by tissues of the rat, guinea-pig or sheep in an endeavour to locate directly the site at which conversion of injected $\beta$-carotene into vitamin A occurs in the normal animal.

2. For this purpose perfusion and incubation experiments were carried out with different forms of $\beta$-carotene and a variety of tissue preparations.

3. Concurrently, parallel experiments were carried out with vitamin A alcohol and aldehyde in an attempt to determine the behaviour of these substances with similar tissue preparations.

4. Despite numerous precautions and the use of several refined techniques, there was no evidence to indicate formation of vitamin A from $\beta$-carotene in any of the organs or tissues examined.

5. Vitamin A alcohol and aldehyde were metabolized by several tissues, their behaviour in vitro being generally similar to that reported independently by other investigators from in vivo experiments.

6. Possible reasons for failure to effect the in vitro conversion of $\beta$-carotene into vitamin $\mathrm{A}$ are discussed and attention is drawn to the fact that it is probably the initial stages of the reaction that are inhibited under in vitro conditions.

\section{REFERENCES}

Ahmad, B. (1934). Curr. Sci. 2, 477.

Ball, S., Goodwin, T. W. \& Morton, R. A. (1948). Biochem. $\mathcal{~} .42,516$.

Bieri, J. G. (1955). Arch. Biochem. Biophys. 56, 90.

Bieri, J. G. \& Pollard, C. J. (1953). Tex. Rep. Biol. Med. II, 402.

Bieri, J. G. \& Pollard, C. J. (1954). Brit. F. Nutr. 8, 32.

Bessey, A. O., Lowry, O. H., Brock, M. J. \& Lopez, J. A. (1946). F. biol. Chem. 166, 177.

Brauer, R. W., Pessotti, R. L. \& Pizzolato, P. (195I). Proc. Soc. exp. Biol., N. Y., 78, 174.

Cama, H. R., Collins, F. D. \& Morton, R. A. (I95I). Biochem. F. 5o, 48.

De, N. K. \& Sundararajan, A. R. (I951). Indian F. med. Res. 39, 479.

Drummond, J. C. \& MacWalter, R. J. (1933). Biochem. F. 27, I342.

Fazakerley, S. \& Glover, J. (1957). Biochem. F. 65, $38 P$.

Fisher, R. B. \& Parsons, D. S. (1949). F. Physiol. r1o, 36.

Fishwick, M. J. \& Glover, J. (1957). Biochem. 7 . 66, $36 P$.

Glover, J., Goodwin, T. W. \& Morton, R. A. (1948a). Biochem. F. 43, rog.

Glover, J., Goodwin, T. W. \& Morton, R. A. (1948b). Biochem. F. 43, 512.

Glover, J. \& Redfearn, E. R. (1954). Biochem. $\mathscr{~}$. 58, xv.

Kon, S. K., McGillivray, W. A. \& Thompson, S. Y. (1955). Brit. F. Nutr. 9, 244.

Kon, S. K. \& Thompson, S. Y. (1951). Brit. F. Nutr. 5, 114.

McGillivray, W. A. (1951). Aust. F. sci. Res. B, 4, 370.

McGillivray, W. A., Thompson, S. Y. \& Worker, N. A. (1956). Brit. F. Nutr, 10, 126.

Moore, T. \& Sharman, I. M. (195I). Brit. F. Nutr. 5, I 19.

Olcott, H. S. \& McCann, D. C. (1931). F. biol. Chem. 94, 185.

Pariente, A. C. \& Ralli, E. P. (I93 I-2). Proc. Soc. exp. Biol., N.Y., 29, I 209.

Rea, J. L. \& Drummond, J. C. (1932). Z. Vitaminforsch. I, 177.

Rosenberg, A. \& Sobel, A. E. (I953a). Arch. Biochem. Biophys. 44, 320.

Rosenberg, A. \& Sobel, A. E. (1953b). Arch. Biochem. Biophys. 44, 326.

Shafiroff, B. G. P., Mulholland, J. H., Roth, E. \& Baron, H. C. (I949). Proc. Soc. exp. Biol., N. Y., 70, 343.

Stallcup, O. T. \& Herman, H. A. (1950). F. Dairy Sci. 33, 237.

Thompson, S. Y., Ganguly, J. \& Kon, S. K. (1949), Brit. F. Nutr. 3, 50.

Umbreit, W. W., Burris, R. H. \& Stauffer, J. F. (1947). Manometric Techniques and Related Methods for the Study of Tissue Metabolism, p. 194. Minneapolis: Burgess Publishing Co. 
von Euler, H. (1932). Ergebn. Physiol. 34, 360.

von Euler, H. \& Klussmann, E. (1932). Hoppe-Seyl. Z. 213, 21.

Wiese, C. E., Mehl, J. W. \& Deuel, H. J. Jr. (1947). Arch. Biochem. 15, 75.

Woolf, B. \& Moore, T. (1932). Lancet, 223, 13.

Worker, N. A. (1956a). Brit. F. Nutr, 1o, 169.

Worker, N. A. (1956b). F. Nutr. 6o, 447 .

Worker, N. A. (1957). Brit. F. Nutr. I1, 44.

\title{
The availability of bound nicotinic acid to the rat
}

\author{
1. The effect of lime-water treatment of maize and \\ subsequent baking into tortilla
}

By E. KODICEK AND P. W. WILSON
Dunn Nutritional Laboratory, University of Cambridge and Medical Research Council

(Received 7 April 1959)

In an earlier paper (Kodicek, Braude, Kon \& Mitchell, 1959) the reviewed evidence showed that maize and other cereals contain almost all their nicotinic acid in a bound form which is unlike any of the known nicotinoyl compounds in being unavailable to rats, dogs, poultry or pigs and, probably, man. For the rat or pig the full biological activity of bound nicotinic acid in maize and other cereals can be released by hydrolysis with $0.5 \mathrm{~N}-\mathrm{NaOH}$, which liberates free nicotinic acid (Chaudhuri \& Kodicek, I950; Kodicek, 195I; Harper, Punekar \& Elvehjem, I958; Kodicek et. al. 1956). Maize cooked with lime-water, as in the preparation of tortilla in Central America and particularly in Mexico, has been reported to cure nicotinic-acid deficiency in rats (Laguna \& Carpenter, 195I; Cravioto, Massieu, Cravioto \& Figueroa, 1952; Squibb, Braham, Arroyave \& Scrimshaw, 1955; Massieu, Cravioto, Cravioto, Guzmán \& Suarez Soto, 1956; Fiorentini, Gaddi \& Bonomolo, 1956; Pearson, Stempfel, Valenzuela, Utley \& Darby, 1957). Kodicek et al. (1959) showed that such treatment of maize releases the full biological activity of nicotinic acid for the pig. However, two other research groups did not observe a curative effect of maize treated with limewater on either rats (Krehl, Henderson, de la Huerga \& Elvehjem, 1946) or man (Goldsmith, Rosenthal, Gibbens \& Unglaub, 1955; Goldsmith, Gibbens, Unglaub $\&$ Miller, 1956). The negative results obtained by the latter group appear to have been due mainly to the small amount of maize in the diet, which would not have contributed significantly to the supply of nicotinic acid even if it had been completely available. Other factors may, however, contribute to the success or failure of lime-water treatment, particularly variations in the method of preparing tortilla, which may determine the extent to which nicotinic acid is liberated.

We have, therefore, re-investigated the lime-water procedure in detail and tested various tortilla preparations, both biologically on nicotinic-acid deficient rats and 